\title{
Putting the Strategy into Action
}

\author{
Lauza Saulnier
}

$\mathrm{F}_{\mathrm{c}}^{\mathrm{o}}$

ollowing an extensive stakeholder consultation process, the

Canadian Society of Hospital Pharmacists (CSHP) now has a new strategic plan aimed at improving pharmacists' practice, member and volunteer engagement, governance, and organizational effectiveness.

The Strategic Plan 2015-2018 highlights the vision that CSHP aims to achieve in the next 3 years: a thriving, progressive society, leading and inspiring excellent pharmacy practice integral to patient-centred care in hospitals and other collaborative healthcare settings. The plan lays out the future direction of the organization, specifies where we will focus our goals, and outlines priorities for improvement.

CSHP's Branches, affiliated Boards, and staff have played key roles in developing the plan, which involved identifying key strategic areas, setting strategic goals, aligning objectives with the plan's strategic goals, and identifying actions to be undertaken. To understand the progress made over the coming years, CSHP will measure performance using a "balanced scorecard", a tool developed by Kaplan and Norton (see Harvard Business Review, 2007;85[7/8]:150-61) for translating a strategy into a set of measures. This tool provides a means of documenting and communicating the strategy to achieve our organization's vision and provides the Board with information to make timely, informed strategic decisions linked to defined outcomes and objectives. These measures will answer the following questions: How are we doing? Are we getting closer to our targets? What other actions are required?

Receiving my 25-year CSHP membership pin last year gave me the opportunity to reflect on the impact of our Society through the advancement of pharmacy practice in hospitals and other collaborative health care settings. My experience as a volunteer with CSHP started when I was a pharmacy resident. Since then, I have served as an Executive Officer of the New Brunswick (NB) Branch, as the NB Branch delegate on CSHP Council, and as a member of the Canadian Pharmacy Residency

Board. I now look forward to joining the CSHP Executive Committee for my 3-year term as Vision Liaison, starting as President Elect for the coming year.

Throughout my career, I have witnessed the growth of our profession and the impact of this change on patients' health outcomes. Measures such

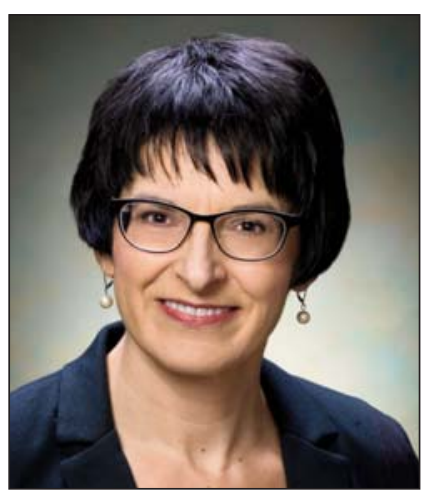
as those published in the Hospital Pharmacy in Canada Report (www.lillyhospitalsurvey.ca/hpc2/content/rep_ 2015_toc.asp) and those included in the CSHP 2015 initiative (www.cshp.ca/cshp2015/index_e.asp) and the American Society of Health-System Pharmacists' Pharmacy Practice Model Initiative (www.ashp.org/ppmi) help in monitoring progress toward objectives, comparing performance with benchmarks, assessing real value delivered to "customers", and identifying improvement opportunities. Performance measures are crucial elements in driving change, as we can't manage what we can't measure!

The key to successful strategy implementation will be to select the measures that best capture desired performance and then to review progress on these measures regularly and report developments to our members, supporters and stakeholders. The CSHP Strategic Plan 2015-2018 is our opportunity to contribute to the achievement of our vision and to put ideas for improvement into action. It is our opportunity to shape our Society for years to come!

Lauza Saulnier, BSc(Pharm), ACPR, became President Elect and Vision Liaison for the Canadian Society of Hospital Pharmacists (CSHP) at the Board meeting following her election during the CSHP Annual General Meeting in August 2015. 